Check for updates

Cite this: Chem. Commun., 2019, 55,5732

Received 28th March 2019 Accepted 17th April 2019

DOI: $10.1039 / c 9 c c 02418 b$

rsc.li/chemcomm

\section{Reduction of 1,3,5,7-cyclooctatetraene by a molecular calcium hydride: an even electron polarised insertion/deprotonation mechanism $\dagger$}

\author{
Michael S. Hill, (D)*a Mary F. Mahon, ${ }^{a}$ Andrew S. S. Wilson, ${ }^{a}$ Chiara Dinoi, ${ }^{b}$ \\ Laurent Maron (D) *b and Emma Richards (D) ${ }^{c}$
}

\begin{abstract}
Reaction of a dimeric $\beta$-diketiminato calcium hydride with 1,3,5,7cyclooctatetraene enables two electron aromatisation of the [8]annulene to provide an inverse sandwich dicalcium cyclooctatetraenyl derivative. This reactivity does not proceed through sequential single electron transfer but via a consecutive polarised $\mathrm{Ca}-\mathrm{H} / \mathrm{C}=\mathrm{C}$ insertion and deprotonation pathway that occurs at the intact dimeric hydride reagent.
\end{abstract}

Harder and co-workers' $\beta$-diketiminato calcium hydride, $[(\mathrm{BDI}) \mathrm{Ca}(\mathrm{THF}) \mathrm{H}]_{2}(\mathbf{1}),{ }^{1,2}\left(\mathrm{BDI}=\mathrm{HC}\left\{(\mathrm{Me}) \mathrm{CN}-2,6-\mathrm{i}-\mathrm{Pr}_{2}\right\}_{2}\right)$ initiated significant interest in molecular hydride derivatives of the heavier alkaline earth elements. Although a variety of dimeric and polynuclear structural types have now been described, ${ }^{3-14}$ even greater interest has arisen from their emergent utility as stoichiometric and catalytic reagents. ${ }^{15-18}$ Compound 1, for example, has been shown to act as a catalyst for the hydrogenation of activated alkene and diene substrates, ${ }^{19}$ a process which typifies the polarised metathetical and $\mathrm{C}=\mathrm{C}$ insertion reactivity mediated by such redox-invariable $2+$ metal centres. Our own research has highlighted that the highly nucleophilic character of the $\mathrm{Ca}-\mathrm{H}$ bond of the THF-free variant of $\mathbf{1}$, $[(\mathrm{BDI}) \mathrm{CaH}]_{2}(2)$, enables its direct reaction with a wide range of unactivated terminal alkenes to provide the corresponding dimeric $n$-alkyl species. ${ }^{20,21}$ Notably, these reactions occur via highly polarised $\mathrm{Ca}-\mathrm{H} / \mathrm{C}=\mathrm{C}$ insertion pathways and through the apparent retention of dimeric hydride and hydrido-alkyl intermediates (Scheme 1). The resultant alkyl derivatives are also sufficiently nucleophilic to effect the heterolytic cleavage of $\mathrm{H}_{2}$ or, ${ }^{22}$ even more remarkably, the direct nucleophilic

\footnotetext{
${ }^{a}$ Department of Chemistry, University of Bath, Claverton Down, Bath, BA2 7AY, UK. E-mail:msh27@bath.ac.uk

${ }^{b}$ Université de Toulouse et CNRS, INSA, UPS, UMR 5215, LPCNO,

135 Avenue de Rangueil, F-31077 Toulouse, France

${ }^{c}$ School of Chemistry, Cardiff University, Park Place, Cardiff CF10 3AT, UK

$\dagger$ Electronic supplementary information (ESI) available: General synthetic experimental details, NMR spectra, details of the X-ray analysis of compound 3, details of the computational analysis and atomic coordinates of the DFT computed structures. CCDC 1906088. For ESI and crystallographic data in CIF or other electronic format see DOI: 10.1039/c9cc02418b
}

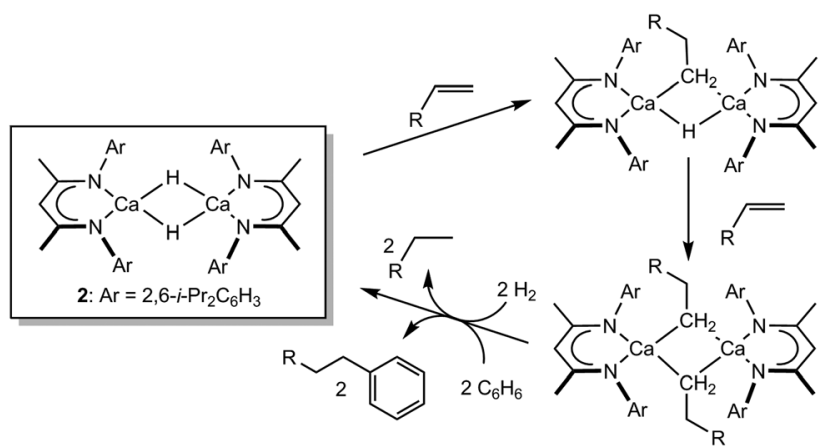

Scheme 1 Reactivity of compound 2 with alkenes and that of the resultant calcium alkyls with $\mathrm{H}_{2}$ and benzene.

displacement of hydride from benzene to provide the corresponding alkylated benzene derivatives. ${ }^{20,23}$

With these observations in mind, our attention was drawn to Harder's recent demonstration of the potency of such hydride reagents toward the transfer hydrogenation of $\mathrm{C}-\mathrm{C}$ multiple bonds. $^{24}$ This chemistry utilised 1,4-cyclohexadiene (1,4-CHD) as the source of dihydrogen during which the cyclic diene is aromatised to benzene. Density functional theory (DFT) calculations demonstrated that this transformation ensues through a sequence of 1,4-CHD deprotonation and hydride elimination from the resultant cyclohexadienyl intermediate. This observation is particularly striking as it exemplifies a formal two electron oxidation of 1,4-CHD, but mediated by a hydridic reagent of a type that is more typically considered as a source of reducing electron equivalents. In this latter context, Evans has raised similar questions with regard to the potential of organolanthanide and actinide hydrides to provide reductive behaviour comparable to lower oxidation state species. ${ }^{25,26}$ A suitable test case was provided by the reduction of 1,3,5,7cyclooctatetraene $\left(1,3,5,7-\mathrm{C}_{8} \mathrm{H}_{8}\right)$ to the cyclooctatetraenyl dianion, $[\mathrm{COT}]^{2-}$, by $\left[\left(\mathrm{C}_{5} \mathrm{Me}_{5}\right)_{2} \mathrm{LnH}\right]_{2}(\mathrm{Ln}=\mathrm{Y}, \mathrm{La}$ and $\mathrm{Sm}),{ }^{26}$ and the thorium hydride $\left[\left(\mathrm{C}_{5} \mathrm{Me}_{5}\right)_{2} \mathrm{ThH}_{2}\right]_{2} \cdot{ }^{25}$ These transformations occur with retention of the oxidation state of the metal and through 
oxidation of the supporting ligands, eliminating either hydrogen gas or $\left(\mathrm{C}_{5} \mathrm{Me}_{5}\right)_{2}$. Although no definitive mechanistic rationale has been presented, the authors' comparison of the $\mathrm{H}_{2} / 2 \mathrm{H}^{-}$reduction potential $\left(E^{\circ}=-2.25 \mathrm{~V}\right)$ with the first and second reduction potentials of $1,3,5,7-\mathrm{C}_{8} \mathrm{H}_{8}$ itself $\left(E^{\circ}=-1.83\right.$ and $\left.-1.99 \mathrm{~V}\right)$, invokes a tacit assumption of sequential single electron reduction steps analogous to those implicated in the direct reduction of $1,3,5,7-$ $\mathrm{C}_{8} \mathrm{H}_{8}$ by alkali metals $\left(\right.$ e.g. $\left.\mathrm{Na}^{+} / \mathrm{Na}, E^{\circ}=-2.71 \mathrm{~V}\right) .^{27-34}$

Structurally characterised alkaline earth complexes comprising the cyclooctatetraenyl dianion are currently limited to examples in which the reducing equivalents of electrons are provided by the unambiguous oxidation of an s-block element centre. The heavier homoleptic alkaline earth complexes, [AeCOT] $(\mathrm{Ae}=\mathrm{Ca}, \mathrm{Sr}$ and $\mathrm{Ba})$, for example, were synthesised by metal vapour co-condensation with $1,3,5,7-\mathrm{C}_{8} \mathrm{H}_{8}$, whilst the magnesium derivative, $\left[\mathrm{Mg}(\mathrm{COT})(\mathrm{THF})_{2.5}\right],{ }^{35,36}$ was accessed through the direct combination of the [8]annulene and magnesium. In a process reminiscent of these 'dissolving metal' reductions, $\left[\{(\mathrm{BDI}) \mathrm{Mg}(\mathrm{THF})\}_{2}(\mathrm{COT})\right]$, has been prepared via the two-electron reduction of $1,3,5,7-\mathrm{C}_{8} \mathrm{H}_{8}$ with the magnesium(I) dimer $[(\mathrm{BDI}) \mathrm{Mg}]_{2}{ }^{37}$ In contrast, a variety of heavier alkaline earth inverse sandwich derivatives, $\left[\left(\mathrm{i}-\mathrm{Pr}_{4} \mathrm{C}_{5} \mathrm{H}\right) \mathrm{Ae}(\mu-\mathrm{COT}) \mathrm{Ae}\left(\mathrm{i}-\mathrm{Pr}_{4} \mathrm{C}_{5} \mathrm{H}\right)\right](\mathrm{Ae}=\mathrm{Ca} \text { and } \mathrm{Ba})^{38}$ and $\left.\left[\left\{\left(\mathrm{Me}_{3} \mathrm{Si}\right)_{2} \mathrm{~N}\right\} \mathrm{Ae}(\mathrm{THF})_{x}\right\}(\mu-\mathrm{COT})(\mathrm{THF})_{x} \mathrm{Ae}\left\{\mathrm{N}\left(\mathrm{SiMe}_{3}\right)_{2}\right\}\right](\mathrm{Ae}=\mathrm{Ca}$, $x=1$; Ae $=\mathrm{Sr}, x=2),{ }^{39}$ have been prepared by salt metathesis of the alkaline earth halide precursors, $\left[\left\{\left(\mathrm{C}_{5} \mathrm{Hi}-\mathrm{Pr}_{4}\right) \mathrm{AeX}(\mathrm{THF})_{2}\right\}_{2}\right]$ $(\mathrm{Ae}=\mathrm{Ca}, \mathrm{X}=\mathrm{Cl} ; \mathrm{Ae}=\mathrm{Ba}, \mathrm{X}=\mathrm{I})$ and $\mathrm{AeI}_{2}(\mathrm{Ae}=\mathrm{Ca}, \mathrm{Sr})$ with disodium cyclooctatetraenide or potassium hexamethyldisilazide and dipotassium cyclooctatetraenide, respectively. In all these latter cases, however, the $[\mathrm{COT}]^{2-}$ dianions were generated by direct reduction of $1,3,5,7-\mathrm{C}_{8} \mathrm{H}_{8}$ by the relevant group 1 metal.

Although alkaline earth hydride-mediated reactivity of 1,3,5,7$\mathrm{C}_{8} \mathrm{H}_{8}$ is yet to be described, the reactions of diphenylacetylene with either compound 2 or a similarly dimeric amidinato calcium hydride have been shown to result in reduction to the stilbene dianion, $[\mathrm{Ph}(\mathrm{H}) \mathrm{C}-\mathrm{C}(\mathrm{H}) \mathrm{Ph}]^{2-} \cdot{ }^{21,40}$ Notably, the reductive reactivity of this latter species toward $\mathrm{I}_{2}$ and $\mathrm{H}_{2}$ led it to being posited as a potential $\mathrm{Ca}(\mathrm{I})$ synthon. With these diverse considerations in mind, we describe herein our observations of the ability of compound 2 to effect the generation of the $[\mathrm{COT}]^{2-}$ dianion.

Addition of one equivalent of $1,3,5,7-\mathrm{C}_{8} \mathrm{H}_{8}$ to a $\mathrm{C}_{6} \mathrm{D}_{6}$ solution of compound 2 was accompanied by the immediate vigorous evolution of gaseous hydrogen (Scheme 2). This observation was accompanied by the appearance of new BDI methine and [COT $]^{2-}$ signals at $\delta 4.49$ and $5.60 \mathrm{ppm}$ with a relative ratio of 2:8 in the resultant ${ }^{1} \mathrm{H}$ NMR spectrum (Fig. S1, ESI $\dagger$ ). A preparative scale reaction $\ddagger$ allowed the solid state structure of the dicalcium cyclooctatetraenyl derivative, $[(\mathrm{BDI}) \mathrm{Ca}(\mu-\mathrm{COT}) \mathrm{Ca}(\mathrm{BDI})](3)$, to be confirmed by a single crystal X-ray diffraction analysis of a crystal grown from a saturated hexane solution at $-35{ }^{\circ} \mathrm{C}$ (Fig. 1). $\S$

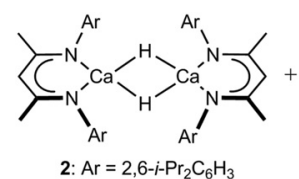

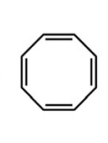
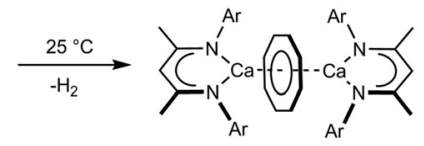

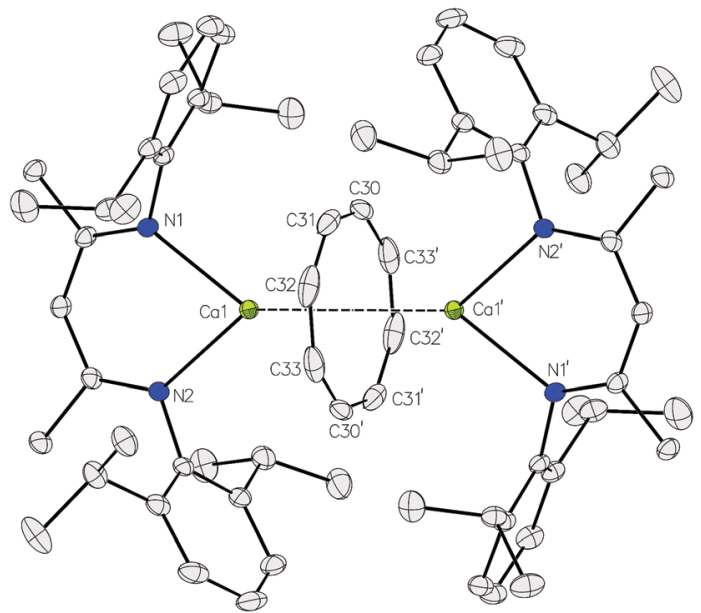

Fig. 1 ORTEP representation of compound $\mathbf{3}$ with thermal ellipsoids at $30 \%$. Hydrogen atoms have been removed for clarity. Selected bond lengths $(\AA)$ and bond angles ( ${ }^{\circ}$ ). Ca1-N1 2.3654(11), Ca1-N2 2.3793(10), Ca1-C30 2.7200(15), Ca1-C30' 2.7175(16), Ca1-C31 2.7121(15), Ca1-C31' 2.7200(16), Ca1-C32 2.7215(17), Ca1-C32' 2.7181(17), Ca1-C33 2.7121(17), Ca1-C33' 2.7181(17),

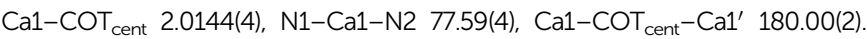
Symmetry operation to generate primed atoms $1-x, 1-y, 1-z$.

The asymmetric unit of compound 3 comprises half of a dimer wherein a crystallographic inversion centre coincident with the centroid of the $\mathrm{C}_{8}$ ring serves to generate the remainder of the molecule. The inverse sandwich structure of 3 is, thus, defined by an $\eta^{8}$-interaction between the $[\mathrm{COT}]^{2-}$ dianion and the calcium centres with a Ca1-COT ${ }_{\text {cent }}$ distance $[2.0144(4) \AA]$ and a Ca1-COT cent $^{-\mathrm{Ca}^{\prime}}$ angle $\left[180.00(2)^{\circ}\right]$ that closely resemble the analogous measurements of $\left[\left(\mathrm{i}-\mathrm{Pr}_{4} \mathrm{C}_{5} \mathrm{H}\right) \mathrm{Ca}(\mu-\mathrm{COT}) \mathrm{Ca}\left(\mathrm{i}-\mathrm{Pr}_{4} \mathrm{C}_{5} \mathrm{H}\right)\right]$ [1.99 and $1.98 \AA$; 173.0 and $175.8^{\circ}$ ] and the very recently reported $\left.\left[\left\{\left(\mathrm{Me}_{3} \mathrm{Si}\right)_{2} \mathrm{~N}\right\} \mathrm{Ca}(\mathrm{THF})\right\}(\mu-\mathrm{COT})(\mathrm{THF}) \mathrm{Ca}\left\{\mathrm{N}\left(\mathrm{SiMe}_{3}\right)_{2}\right\}\right][2.02$ and $2.04 \AA$ $\left.179^{\circ}\right] .^{38,39}$ The coordination sphere of calcium is completed by the $\beta$-diketiminate ligand with orthodox calcium-nitrogen distances [2.3654(11) and 2.3793(10) ̊̊].

As outlined above, the synthesis of compound 3 raises a number of significant questions with regard to the mode of delivery of the necessary reducing equivalents of electrons to produce the $[\mathrm{COT}]^{2-}$ dianion. The potassium and sodium reduction of $1,3,5,7-\mathrm{C}_{8} \mathrm{H}_{8}$ to the $10 \pi$ aromatic dianion has been shown to occur in a stepwise fashion via the initial generation of the $[\mathrm{COT}]^{-}$radical anion, which is readily identifiable from its characteristic nine line EPR spectrum $\left[a\left({ }^{1} \mathrm{H}\right)=3.2 \mathrm{G}(8.9 \mathrm{MHz})\right] \cdot{ }^{27-29}$ The reaction between compound 2 and 1,3,5,7- $\mathrm{C}_{8} \mathrm{H}_{8}$ in benzene solution was, thus, repeated between 140 and $298 \mathrm{~K}$ within the cavity of an X-band CW EPR spectrometer. Although this procedure again provided for the facile generation of the $[\mathrm{COT}]^{2-}$ dianion, no definitive evidence for any radical intermediates en route to compound 3 were observed. The formation of compound 3 was, therefore, studied by density functional theory (DFT, B3PW91) calculations.

Although different pathways were computed (see ESI $\dagger$ ), only the lowest energy process is presented (Fig. 2). We have previously reported that the dissociation of the dimeric structure of compound 2 is endothermic by some $40.4 \mathrm{kcal} \mathrm{mol}^{-1}$. $^{22}$ Consistent with the facile production of $\mathbf{3}(\mathbf{G})$ at room temperature,

Scheme 2 Synthesis of compound 3 


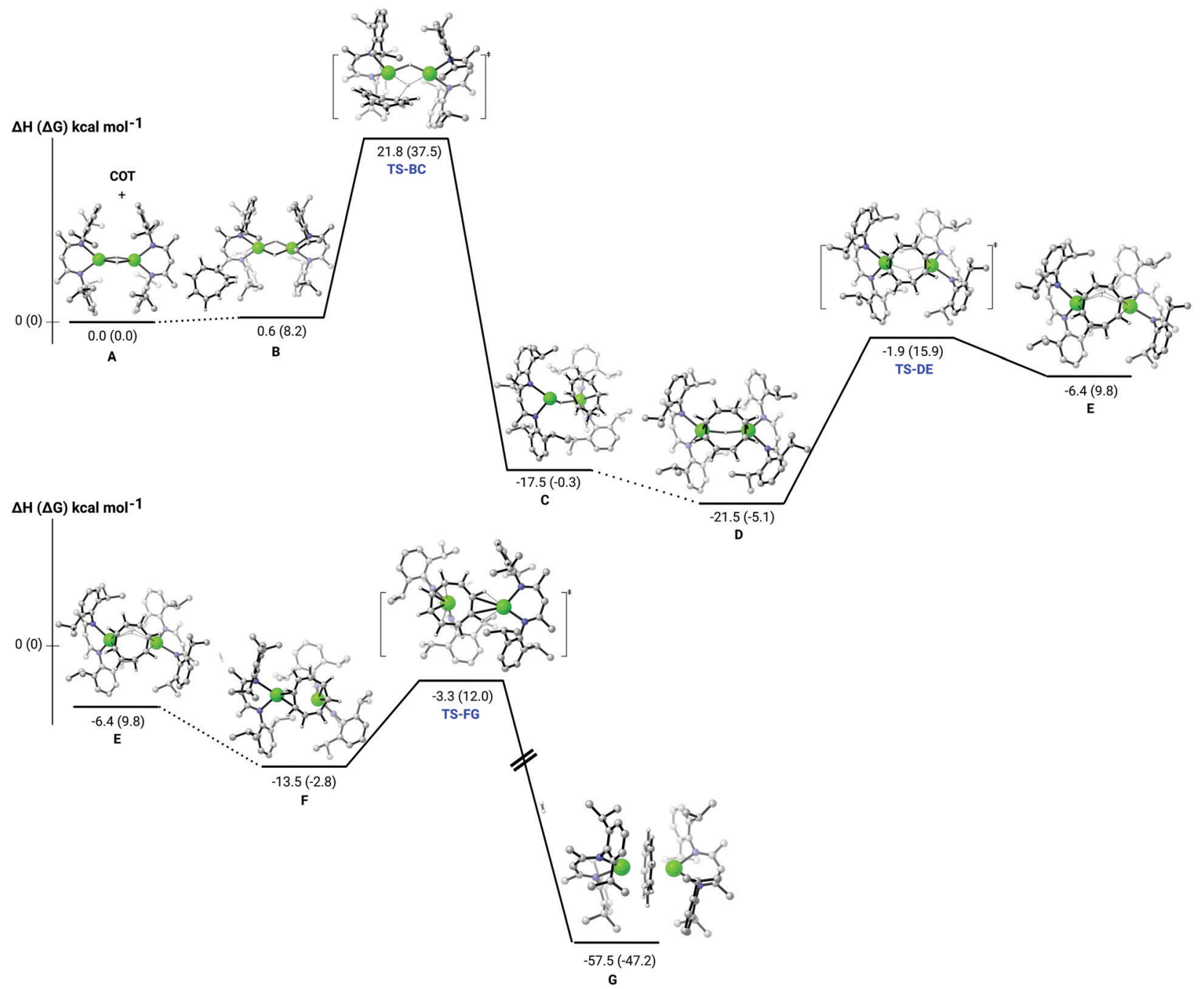

Fig. 2 DFT (B3PW91) computed enthalpy reaction profile at room temperature for the reaction of compound $2(\mathbf{A})$ and 1,3,5,7- $\mathrm{C}_{8} \mathrm{H}_{8}$.

the current analysis (Fig. 2) indicates that the significantly exothermic reaction $\left(\Delta H=-57.5 \mathrm{kcal} \mathrm{mol}^{-1}\right)$ takes place through the retention of the calcium hydride dimer. The rate determining process of the reaction (TS-BC) is provided by the nucleophilic delivery of hydride to one of the isolated $\mathrm{C}=\mathrm{C}$ bonds of the unsaturated [8]annulene. In line with the requisite room temperature conditions, this process occurs via a barrier of $21.2 \mathrm{kcal} \mathrm{mol}^{-1}$ to yield an initial dicalcium cyclooctatrienyl intermediate $(\mathbf{C})$, which also retains a single $\mu_{2}-\mathrm{Ca}-\mathrm{H}-\mathrm{Ca}$ bridging interaction. Subsequent reaction of this $\left\{\mathrm{C}_{8} \mathrm{H}_{9}\right\}^{-}$-containing species (D) requires the traversal of a further kinetically accessible transition state (TS-DE, $19.6 \mathrm{kcal} \mathrm{mol}^{-1}$ ) to provide an aromatisation step that may be viewed as an intramolecular deprotonation of the $\left\{\mathrm{C}_{8} \mathrm{H}_{9}\right\}^{-}$methylene by the remaining hydridic hydrogen centre. Subsequent rearrangement of the two $\{(\mathrm{BDI}) \mathrm{Ca}\}$ units is then facile to provide the bis- $\eta^{8}$-inverse sandwich structure of compound $\mathbf{3}(\mathbf{G})$.

These observations underscore the ability of compound 2 to function as a potent source of polarised unsaturated insertion $(2 \sigma-2 \pi)$ and metathetical $(2 \sigma-2 \sigma)$ reactivity, in this case to demonstrate that the reductive aromatisation of cyclooctatetraene does not necessarily require the intermediacy of single electron or radicaloid intermediates. The broader significance of these observations may lie in their potential relevance to reductive processes mediated by other redox inactive metal hydrides. We are, therefore, continuing to consider the implications of this investigation with regard to the activation of a wider array of reducible annulene and arene substrates.

\section{Conflicts of interest}

There are no conflicts to declare.

\section{Notes and references}

$\ddagger$ A toluene $(10 \mathrm{ml})$ solution of $1,3,5,7-\mathrm{C}_{8} \mathrm{H}_{8}(226 \mu \mathrm{l}, 2.01 \mathrm{mmol})$ was added dropwise at room temperature to a stirring toluene $(10 \mathrm{ml})$ of 2 $(0.92 \mathrm{~g}, 1.00 \mathrm{mmol})$ and stirred overnight ( $c a .16$ hours). The resulting orange solution was evaporated to dryness, redissolved in hexane $(20 \mathrm{ml})$, cannula filtered and concentrated. Pale-yellow crystals deposited at $-35{ }^{\circ} \mathrm{C}$ overnight and were collected via cannula filtration to yield 3 $(0.35 \mathrm{~g}, 34 \%)$. Colourless crystals suitable for X-ray diffraction analysis were obtained from a saturated hexane solution at $-35{ }^{\circ} \mathrm{C} .{ }^{1} \mathrm{H}$ NMR 
(500 MHz, benzene- $\left.\mathrm{d}_{6}\right) \delta 7.28-7.19(\mathrm{~m}, 12 \mathrm{H}, \mathrm{Ar}-H), 5.61\left(\mathrm{~s}, 8 \mathrm{H}, \mathrm{C}_{8} H_{8}\right)$, $4.49\left(\mathrm{~s}, 2 \mathrm{H}, \mathrm{NC}\left(\mathrm{CH}_{3}\right) \mathrm{CH}\right), 2.61$ (hept, $\left.{ }^{3} J_{\mathrm{HH}}=6.8 \mathrm{~Hz}, 8 \mathrm{H}, \mathrm{CH}\left(\mathrm{CH}_{3}\right)_{2}\right), 1.49$ $\left(\mathrm{s}, 12 \mathrm{H}, \mathrm{NC}\left(\mathrm{CH}_{3}\right) \mathrm{CH}\right), 1.44\left(\mathrm{~d},{ }^{3} \mathrm{~J}_{\mathrm{HH}}=6.8 \mathrm{~Hz}, 24 \mathrm{H}, \mathrm{CH}\left(\mathrm{CH}_{3}\right)_{2}\right), 1.01(\mathrm{~d}$, $\left.{ }^{3} J_{\mathrm{HH}}=6.8 \mathrm{~Hz}, 24 \mathrm{H}, \mathrm{CH}\left(\mathrm{CH}_{3}\right)_{2}\right) \mathrm{ppm} .{ }^{13} \mathrm{C}\left\{{ }^{1} \mathrm{H}\right\}$ NMR $(126 \mathrm{MHz}$, benzene$\left.d_{6}\right) \delta 165.1\left(\mathrm{NC}\left(\mathrm{CH}_{3}\right) \mathrm{CH}\right), 146.9\left(C_{\text {ipso }}\right), 141.9\left(C_{\text {ortho }}\right), 124.6\left(C_{\text {para }}\right), 123.7$ $\left(C_{\text {meta }}\right), \quad 93.8\left(\mathrm{NC}\left(\mathrm{CH}_{3}\right) \mathrm{CH}\right), \quad 89.6\left(C_{8} \mathrm{H}_{8}{ }^{2-}\right), 28.9\left(\mathrm{CH}\left(\mathrm{CH}_{3}\right)_{2}\right), 24.6$ $\left(\mathrm{CH}\left(\mathrm{CH}_{3}\right)_{2}\right), 24.5\left(\mathrm{NC}\left(\mathrm{CH}_{3}\right) \mathrm{CH}\right), 24.2\left(\mathrm{CH}\left(\mathrm{CH}_{3}\right)_{2}\right) \mathrm{ppm}$. Despite repeated attempts, the extreme air-sensitivity of this compound precluded the acquisition of an accurate microanalysis.

$\S$ X-ray diffraction data for $3 . \mathrm{C}_{66} \mathrm{H}_{90} \mathrm{Ca}_{2} \mathrm{~N}, M=1019.57$, monoclinic, $P 2_{1} / n, a=14.7014(4), b=10.3339(3), c=19.8975(5) \AA, \beta=92.412(2)^{\circ}$, $V=3020.21(14) \AA^{3}, Z=2, \rho=1.121 \mathrm{~g} \mathrm{~cm}^{-3}$, temperature 150.01(10) K, $R_{1}[I>2 \sigma(I)]=0.0401, \mathrm{w} R_{2}[I>2 \sigma(I)]=0.1042, R_{1}$ [all data] $=0.0423, \mathrm{w} R_{2}$ [all data $]=0.1068$, measured reflections $=37686$, unique reflections $=$ $6031, R_{\text {int }}=0.0617$.

1 S. Harder and J. Brettar, Angew. Chem., Int. Ed., 2006, 45, 3474-3478. 2 J. Spielmann and S. Harder, Chem. - Eur. J., 2007, 13, 8928-8938.

3 S. Harder, Chem. Commun., 2012, 48, 11165-11177.

4 A. Causero, G. Ballmann, J. Pahl, C. Farber, J. Intemann and S. Harder, Dalton Trans., 2017, 46, 1822-1831.

5 B. Maitland, M. Wiesinger, J. Langer, G. Ballmann, J. Pahl, H. Elsen, C. Farber and S. Harder, Angew. Chem., Int. Ed., 2017, 56, 11880-11884.

6 M. Wiesinger, B. Maitland, C. Farber, G. Ballmann, C. Fischer, H. Elsen and S. Harder, Angew. Chem., Int. Ed., 2017, 56, 16654-16659.

7 P. Jochmann, J. P. Davin, T. P. Spaniol, L. Maron and J. Okuda, Angew. Chem., Int. Ed., 2012, 51, 4452-4455.

8 V. Leich, T. P. Spaniol and J. Okuda, Inorg. Chem., 2015, 54, 4927-4933.

9 V. Leich, T. P. Spaniol, L. Maron and J. Okuda, Angew. Chem., Int. Ed., 2016, 55, 4794-4797.

10 D. Schuhknecht, C. Lhotzky, T. P. Spaniol, L. Maron and J. Okuda, Angew. Chem., Int. Ed., 2017, 56, 12367-12371.

11 D. Mukherjee, D. Schuhknecht and J. Okuda, Angew. Chem., Int. Ed., 2018, 57, 9590-9602.

12 D. Mukherjee, T. Hollerhage, V. Leich, T. P. Spaniol, U. Englert, L. Maron and J. Okuda, J. Am. Chem. Soc., 2018, 140, 3403-3411.

13 C. N. de Bruin-Dickason, T. Sutcliffe, C. A. Lamsfus, G. B. Deacon, L. Maron and C. Jones, Chem. Commun., 2018, 54, 786-789.

14 X. H. Shi, C. P. Hou, C. L. Zhou, Y. Y. Song and J. H. Cheng, Angew. Chem., Int. Ed., 2017, 56, 16650-16653.

15 S. Harder, Chem. Rev., 2010, 110, 3852-3876.
16 A. G. M. Barrett, M. R. Crimmin, M. S. Hill and P. A. Procopiou, Proc. R. Soc. A, 2010, 466, 927-963.

17 M. R. Crimmin and M. S. Hill, in Alkaline-Earth Metal Compounds: Oddities and Applications, ed. S. Harder, 2013, vol. 45, pp. 191-241.

18 M. S. Hill, D. J. Liptrot and C. Weetman, Chem. Soc. Rev., 2016, 45, 972-988.

19 J. Spielmann, F. Buch and S. Harder, Angew. Chem., Int. Ed., 2008, 47, 9434-9438.

20 A. S. S. Wilson, M. S. Hill, M. F. Mahon, C. Dinoi and L. Maron, Science, 2017, 358, 1168-1171.

21 A. S. S. Wilson, M. S. Hill and M. F. Mahon, Organometallics, 2019, 38, 351-360.

22 A. S. S. Wilson, C. Dinoi, M. S. Hill, M. F. Mahon and L. Maron, Angew. Chem., Int. Ed., 2018, 57, 15500-15504.

23 S. Harder, B. Rösch, T. Xaver Gentner, H. Elsen, J. Langer and M. Wiesinger, Angew. Chem., Int. Ed., 2019, 58, 5396-5401.

$24 \mathrm{H}$. Bauer, K. Thum, M. Alonso, C. Fischer and S. Harder, Angew. Chem., Int. Ed., 2019, 58, 4248-4253.

25 W. J. Evans, K. A. Miller, S. A. Kozimor, J. W. Ziller, A. G. DiPasquale and A. L. Rheingold, Organometallics, 2007, 26, 3568-3576.

26 W. J. Evans, B. M. Schmiege, S. E. Lorenz, K. A. Miller, T. M. Champagne, J. W. Ziller, A. G. DiPasquale and A. L. Rheingold, J. Am. Chem. Soc., 2008, 130, 8555-8563.

27 F. J. Smentowski and G. R. Stevenson, J. Am. Chem. Soc., 1967, 89, 5120.

28 F. J. Smentowski and G. Stevenson, J. Am. Chem. Soc., 1969, 91, 7401.

29 F. J. Smentowski and G. R. Stevenson, J. Phys. Chem., 1969, 73, 340.

30 P. I. Kimmel and H. L. Strauss, J. Phys. Chem., 1968, 72, 2813.

31 G. R. Stevenson and J. G. Concepcion, J. Phys. Chem., 1972, 76, 2176.

32 G. R. Stevenson and J. G. Concepcion, J. Am. Chem. Soc., 1973, 95, 5692-5694.

33 G. R. Stevenson and I. Ocasio, Tetrahedron Lett., 1976, 427-430.

34 K. Mullen, Chem. Rev., 1984, 84, 603-646.

35 H. Lehmkuhl, S. Kintopf and K. Mehler, J. Organomet. Chem., 1972, 46, C1-C2.

36 T. Alonso, S. Harvey, P. C. Junk, C. L. Raston, B. Skelton and A. H. White, Organometallics, 1987, 6, 2110-2116.

37 S. J. Bonyhady, S. P. Green, C. Jones, S. Nembenna and A. Stasch, Angew. Chem., Int. Ed., 2009, 48, 2973-2977.

38 M. D. Walter, G. Wolmershäuser and H. Sitzmann, J. Am. Chem. Soc., 2005, 127, 17494-17503.

39 F. M. Sroor, L. Vendier and M. Etienne, Dalton Trans., 2018, 47, 12587-12595.

40 A. Causero, H. Elsen, G. Ballmann, A. Escalona and S. Harder, Chem. Commun., 2017, 53, 10386-10389. 